\title{
THE SELF-CONCEPTION OF THE SETU WOMAN KSENIA MÜÜRSEPP
}

\section{Merili Metsvahi}

\begin{abstract}
The article analyses a section of the interview conducted with a 90-yearold Setu woman Ksenia Müürsepp in April 2001. Ksenia came from the Setu area, but the last ten years of her life she resided in Tartu. In the analysed section the informant reflected her life situation in the Tartu period and shed light on her self-conception. Methodical tools of cognitive semantics by George Lakoff and Mark Johnson as well as anthropological theory of cultural models are used in the analysis. The author concludes that the system of metaphors focusing of the concept of self varies from culture to culture. Regarding the identity of Ksenia Müürsepp, the author highlights that the cultural schemas used for self-comprehension in different periods of her life, have changed. She shows that religious matters became more important in critical periods and in the periods when social relations played less important role in informant's everyday life.
\end{abstract}

Keywords: cognitive semantics, folk religion, personal experience narrative, self-conception, Setu culture

\section{INTRODUCTION}

A year ago I wrote an article about how the Setu ${ }^{1}$ woman Ksenia Müürsepp (18.01.1911-17.08.2004), who resided since the year 1995 in Tartu, told my colleagues and me the legend of St. George five times. My article focused on the range of and reasons for variation in the story as told by Ksenia (see Metsvahi 2002; Metsvahi 2003). As she was an exceptional narrator, the material offered extremely interesting analytic possibilities that enabled me tackle issues related to visual imagination, episodic and semantic memory, narrative strategies and religious thinking. However, as Ksenia never told the legend of St. George on her own initiative but always in response to our request to do so, in the end we felt as if we had made her a mere tool of our folkloristic experiment. During my field trips I had experienced one-sided self-exposure more than once, but making Ksenia change her relation to the ontological status of the events of the legend in order to serve the interests of our research project seemed at some point having pushed it too far. 
On one of those moments I made up my mind to focus in my future research not on those sections of the interviews where Ksenia was directly responding to our questions or where her response seemed to be influenced by our expectations but on the sections that display to a greater extent Ksenia's own choice of subject matter. Such moments occurred when in the course of the interview after responding to our question or after the traditional telling of a folktale there was a pause ${ }^{2}$ and Ksenia was free to choose the topic herself. As it turned out, it was on such moments that she made most explicit references to her self-conception and identity.

In the present article I have chosen for the analysis a section of the interview conducted with Ksenia which started with a personal experience narrative relating the present and was followed by a description of Good Friday from Ksenia's younger days. The switch to the description of Good Friday that may seem surprising can be explained by the fact that the interview was conducted shortly before Easter (11.04.2001). As an optimistic person, Ksenia might have chosen the topic also in order to return to a more positive topic after relating a problematic aspect of her present life. Easter might have been a topic that Ksenia related to the social world in Setumaa where she felt at home and which was now available to her only via reminiscence.

The section was preceded by a narration of the legend of St. George that I had asked her to narrate. Before telling the story Ksenia explained that in the old calendar St. George's day was on May 6th and described the icon of St. George in St. George's Church in Värska. This was followed by sentences:

Then people said... when the service was over then they took... they didn't take that big one but a smaller icon and carried it around the church. And people all followed them. And then it was said that who is sick should go ... and then pray to St. George. And he will help if you can touch the icon even a little with your hand.

From here Ksenia continued with a personal experience narrative:

Well, I was taken ill, too. At that time, I was already in Pechora, I lived there. I was ill. And I, too, went to Värska. But the crowds 
there are so vast... Everybody pushing towards that holy image... Some want to lift it, others just to touch. So I could but lay my hand on it for a while and walk a little way, holding it. But I got better. I found a doctor who understood what illness I had. Yeah, and then... Earlier I didn't know. Just felt it was hard to breathe and hard to breathe - but I had no idea what it was. Then that doctor, he found it out. That really was a wise doctor. Then he told me: "When is it that you find it hard to breathe, is it when you go uphill or when you go down?" I told him: "It is hard when I go up, easier when I go down." Then he told me it was cardiac asthma that I must take care or it may affect the lungs, too, and then I would find it even more difficult to breathe. Then I had this - little case of white pills, about this long, very small pills, like... When I felt bad I put one under my tongue. And with these pills I got well.

And now I live. You see how long. I wouldn't have believed I could live so long. And this life now, it's no longer good or fun to live. But, well, you have life in you, what can you do. I can't... You may put me on a heap of money and I shall starve upon that heap. I can't go shopping any more, to buy me food or do anything. Only if they bring it to me, then [Laughs] then I can. But I'm no good for anything. What's the use of such a person? [Merili laughs: Well, I can see what use there is... Ksenia does not hear the comment] You have breath, you have eyes, you have life [Laughs]. So. That's the way it is.

But nowadays... It's there nowadays, too. It's there on Good Friday. The image of Christ is brought from the monastery and put in the centre of the church, a chest like this, with Him inside-His image, of course. And flowers are put there and all, and people come like this to worship Him, believers do. And on Saturday they are in the church all night, too [---]. (ERA, MD 105 (14-15)).

The culture where Ksenia came from differs considerably from my own background. At the same time it would not make sense to claim that Ksenia was a typical representative of the Setu culture neither to research her narratives and modes of self-expression as having implications within the framework of the Setu culture only. My objective is to study the verbal expression of a concrete indi- 
vidual who lived in an apartment building in Tartu but came from Setumaa and had lived most of her life in the context of Setu culture. As an immigrant, in a way, confined to an apartment in a block of flats in the Annelinna region in Tartu, the Setu culture had become even more important to Ksenia. An opportunity to participate in the social life of her community was replaced by memories and reflexive contemplations. Ksenia's willingness to cooperate with folklorists indicated that retelling old stories and talking about the past helped Ksenia to consolidate her identity and to partially cope with the absence of the Setu socio-cultural context.

The first reason why the extract highlighted above in bold caught my attention was that it was one of the most self-reflexive sections of all interviews with Ksenia and one of the few where Ksenia was trying to redefine her self in the present life-situation. It is also noteworthy that although the extract is characteristic in its selfreflexivity of post-traditionalist intimate society it makes use of quite expressive traditional means of expression. In addition to the mode of fluent verbal expression characteristic of the Setu culture, the extract also contains phrases typical of contemporary discourse. For example, the phrase 'this life now, it's no longer good or fun to live' conveys the way of thinking typical of the present. Crisis situation of a kind is expressed most explicitly via the tension between the phrase hing seeh, silmaq pääh, elo man 'You have breath, you have eyes, you have life' and the metaphor of the raharõuk 'heap of money'.

Before I'll continue with the analysis I shall introduce two approaches within the field of cognitive science, the methodical tools and terminology I am going to use.

\section{RECENT APPROACHES IN COGNITIVE LINGUISTICS: GEORGE LAKOFF AND MARK JOHNSON}

Several areas of scholarly research focusing on the individual, language and culture have recently witnessed an increasing popularity of cognitive approaches. The exact definition of cognitive studies depends on the theoretical frameworks used by different researchers. Cognitive psychologists Herbert A. Simon and Craig A. Kaplan have provided the following definition: "Cognitive science is the study 
of intelligence and intelligent systems, with particular reference to intelligent behaviour as computation" (1989: 1). The emergence of cognitive science is related to the development of technological possibilities for investigating human cognition. In 1956 the concept of "artificial intelligence", referring to the widening of the applicability of the concept of intelligence from human beings and animals extended also to computers (Simon \& Kaplan 1989: 4). Several decades later, scientists came to realize that it is not possible to create an intelligent machine ${ }^{3}$ (e.g. Johnson-Laird 1989: 490) and new methods and means of analyzing human reason and cognitive processes had to be found.

Linguist George Lakoff and philosopher Mark Johnson, working in the field of cognitive semantics, who are among the key figures of the new approach, claim that cognitive science can be viewed as "the scientific discipline that studies conceptual systems" (2001: 10). They have consciously refrained from using the concept "intellectual" as they do not consider categorization a purely intellectual process (Lakoff \& Johnson 2001: 19). According to Lakoff and Johnson, the formation and utilization of categories is directly related to experience, which in turn, is inseparable from our body and brain. Thus reason on the one hand and perception and motor control on the other are based on the same mechanisms. Our capacity to successfully cope with the surrounding physical environment rests on the fact that our categories of understanding the world have developed from our sensorimotor systems (ibid.: 4-43; 139). They go even furher and state the following:

Our concepts cannot be a direct reflection of external, objective, mind-free reality because our sensorimotor system plays a crucial role in shaping them. On the other hand, it is the involvement of the sensorimotor system in the conceptual system that keeps the conceptual system very much in touch with the world. (Lakoff \& Johnson 2001: 44).

An important part of this radical new approach, refuting the Cartesian body-mind dualism, is a theory of metaphors that views them not as the result of interpretative processes but as "a matter of immediate conceptual mapping via neural connections" (Ibid.: 57). When thinking of our experience and in making decisions we always employ metaphors, also referred to as primary (conceptual) 
metaphors by Lakoff and Johnson. Both the acquisition and the employment of metaphors take place in automatic and unconscious manner (ibid.: 59). According to Lakoff and Johnson:

Our most important abstract concepts, from love to causation to morality, are conceptualized via multiple complex metaphors. Such metaphors are an essential part of those concepts, and without them the concepts are skeletal and bereft of nearly all conceptual and inferential structure. (Lakoff \& Johnson 2001: 73).

Philosophers have presented multiple arguments in defence of their theories, overlooking the metaphorical nature of their arguments. In other words, what they failed to account for is that "the cognitive reality is that our concepts have multiple metaphorical structurings" (ibid.: 71). As reality together with descriptions and categorizations does not exist separately from our mind, traditional theories of truth relying on the dichotomic relationship of the object and the subject can be called into question. The innovative theoretical framework, "embodied scientific realism", proposed by Lakoff and Johnson, juxtaposing itself to classical correspondence theory of truth that grants no role to our sensorimotor system, brain and body, relies on an understanding that "we are coupled to the world through our embodied interactions" (ibid.: 93, 102). "Embodiment of concepts" exists on at least three levels: "the neural level, phenomenological conscious experience, and the cognitive unconscious". ${ }^{4}$ In order to comprehend the human mind adequately, we need to consider all three levels: as well as the fact that these three levels are interrelated (ibid.: 102-104).

In their work "Philosophy in the Flesh" Lakoff and Johnson investigate metaphors related to various abstract phenomena. In the chapter titled "The Self" Lakoff and Johnson argue that the whole system of metaphors focusing of the concept of self is based on a fundamental distinction between the "subject" and one or more "selves" (ibid.: 268-269). Our centre is thinking "subject". Self or selves are those aspects of us that are related to our body, social roles and activities. Each self is metaphorically understood through a person, object or place. Lakoff and Johnson group metaphors related to the concept of the self under various base metaphors. In order to demonstrate the underlying principles of the distinction 
between the subject and the self, I will outline a few examples of different types of metaphors.

In the sentence 'I held myself back from hitting him' the subject as a physical object is holding back the self as his body. In the sentence 'pull yourself together' the subject is perceived as a person and the scattered position of the self in space as dispersion of attention, while a self concentrated in one location indicates concentration of attention, i.e. the normal state of mind. The metaphoric expression 'I promised myself a vacation' is based on social relations: the subject is a person who promises and self is the person who is the recipient of the promise (ibid.: $276 ; 278$ ).

Lakoff and Johnson take as their starting point the idiomatic structure of the English language, occasionally also using examples from other languages. In the chapter "The Self" the authors also use examples from Japanese where the inner life of a person is expressed via metaphors that are comparable to those in English (ibid.: 284-287). Although many examples also have Estonian equivalents, the system of self-metaphors should not be identical from language to language.

\section{ANTHROPOLOGICAL THEORY OF CULTURAL MODELS}

As cognitive research has to a great extent foregrounded issues related to the organization of knowledge, cognitive theories abound with discussion of models and systems. Anthropologists informed by cognitive insights, viewing culture as "an information-holding system" (D'Andrade 1984: 89), have introduced various cognitive concepts containing the word "cultural", such as, for example, "cultural meaning systems" (D'Andrade 1984) and "cultural models" (Quinn \& Holland 1987). D'Andrade has also formulated the definition of a cultural model as a "cognitive schema that is intersubjectively shared by a social group" (1989: 809). Viewing cultural models as "intersubjectively shared", D'Andrade claims "interpretations made about the world on the basis of a cultural model are experienced as obvious facts of the world" (1989: 809).

Cognitive anthropologists have generally adopted such approach to culture and in cases where problems have arisen in application; the 
concept has been reviewed, not discarded. The first range of problems stemmed from attempts to categorize and analyze human behaviour according to such model. It turned out that the majority of behavioural acts did not lend itself to reduction of knowledge (or its representation) and a distinction between "representational" and "operational" cultural models (Quinn \& Holland 1987: 8) or between "constitutive" and "regulatory" norms (D'Andrade 1984: 93) came into being. Soon more flexible frameworks replaced the knowledgeoperation distinction. Melford Spiro differentiated between five levels of cognitive salience, "with which the cultural doctrines are acquired as personal beliefs". If on the first level "the actors learn about the doctrines [and] acquire an "acquaintance" with them", then on the fifth level "as genuine beliefs the doctrines not only guide, but also serve to instigate action; [and] possess motivational as well as cognitive properties [---]" (Spiro 1987: 163-164).

Roy G. D'Andrade's approach, in its essence analogous to that of Spiro, employs different terminology. D'Andrade's initial scheme that he used to surpass the knowledge-action dichotomy, was based on an adaptation of Searle's speech act theory to his theory of culture; D'Andrade attributed four functions to cultural meaning: representational, constructive, directive and evocative (1992: 36; 1984: 96). Later, when a need for more easily applicable theory emerged, D'Andrade focused on the study of motivation. According to him, many cultural schemes (cultural models according to other authors) function as objectives. In order to

understand people one needs to understand what leads them to act as they do, and to understand what leads them to act as they do one needs to know their goals, and to understand their goals one must understand their overall interpretive system, part of which constitutes and interrelates these goals, and to understand their interpretive system - their schemes - one must understand something about the hierarchical relationships among these schemes (D'Andrade 1992: 31).

D'Andrade's theory has been put into practice by many anthropologists. In her analysis that is based on the interviews conducted with American women on marriage-related inner conflicts, Quinn presupposes that cultural models can have motivating impact. Cultural models or schemas acquire importance and motivate people to act 
when they contribute to the understanding of the self ${ }^{5}$ (Quinn 1992: 91). Quinn divides self-understanding into three different schemas: "One kind of schema defines the self as a human being among other such beings who observe some standard of equitable relations with one another ("how I should be treated and treat others"); another defines the self as the occupant of social roles with obligations attached to them ("what someone in my position ought to do"); and the last defines the self as possessor of inherent attributes or traits ("what I am like") (Quinn 1992: 92). The inner conflicts of the interviewed women, according to Quinn, stem from the fact that the selfunderstanding of different schemas does not coincide (ibid.).

In my opinion, Quinn's schemas can be explained through author's own psychology and certain assumptions of (the Western) culture rather than through the cultural models in the mind of the interviewed women. At the same time, however, I do not deny the capacity of verbalized thoughts and narratives produced by the informants during the interviews to lend itself to generalizations that reflect self-conception characteristic of a specific culture.

Claudia Strauss, in her research focusing on the life and "success values" of American male informants, comes to the conclusion that

for most of my interviewees, success values are stored as the packets of knowledge postulated in traditional schema theory, while their wide-ranging personal semantic networks are stored in a less packaged way. The success model comes to their consciousness as a set of values, while the breadwinner model (though it contains values as well) often comes to their consciousness in a different way, as knowledge of reality (Strauss 1992: 219).

The above quoted extract by Strauss reveals the operation of the same knowledge-action dichotomy that the efforts of cognitive anthropologists were directed against. This, however, does not mean that these scholars support the Cartesian dualism, the refutation of which was the triggering force for the thought of Lakoff, Johnson and the psychologist Antonio Damasio. ${ }^{6}$ On the contrary: cognitive anthropologists are well aware of that Achilles heel of Western thought. Spiro, for example, claims that "culture does not consist of thought (thinking) any more than it consists of emotion (feeling)" (1984: 324) and Quinn and Holland believe that the division of cultural understanding into knowledge and operation refers more to 
the juxtaposition of thought and body in Western thought than to the actual organization of cultural knowledge (1987: 8-9).

\section{THE ANALYSIS OF KSENIA MÜÜRSEPP'S SELF- CONCEPTION}

The phrase hing seeh, silmaq pääh, elo man 'You have breath, you have eyes, you have life' and the metaphor of the raharõu 'heap of money' used by Ksenia indicate that the section quoted in the beginning of the article expresses a different worldview and self-conception than typical of contemporary culture. I am basing my claim on Lakoff's and Johnson's semantic analysis grounded on their theory of self-metaphors. An analysis of the sections of interviews with Ksenia where she touched upon her self-conception reveals no metaphors where the subject and the self (or selves) could be identified in the way it is done by Lakoff and Johnson. Ksenia did not use expressions where her inner or nuclear self would have been in opposition with another self. Neither did she claim that her real self yearned for a different kind of life. Ksenia did not often foreground occasions where she used the first person singular pronoun 'I'. Sometimes she even seemed to avoid it; when asking "What's the use of such a person?" she seemed to be referring to another person.

The expression hing seeh, silmaq pääh, elo man 'You have breath, you have eyes, you have life' that demonstrates Ksenia's good cultural knowledge unites both the spiritual and the corporeal in antiCartesian manner. In doing so the metaphor does not follow the logic of the metaphors of the self outlined by Lakoff and Johnson where subject representing the mind and the self representing the body are opposed to each other. According to Ksenia, the essential qualities that define a human being are not hidden in the labyrinths of the mind but relate a human being to the world through embodied interactions. One conclusion that can be drawn from this is that the system outlined by Lakoff and Johnson, based on IndoEuropean languages is culture specific and cannot be applied to all cultures.

One of the important aspects of the self that was formulated by Ksenia is agency. Raharõuk 'heap of money' as formulated by Ksenia 
stands for all goods outside the self that although being within the reach of the self, remain unattainable. On such occasions Ksenia did not use concrete primary metaphors directed toward action within and outside one's reach but expressed inability via a much larger and more general image of dying. If life is looked upon as a force that energizes and motivates human beings, death and dying refer to the ceasing of that force. Eyes can see the raharõuk and soul desires it but there is not enough life force that would make possible to fulfilling the desire of the soul. The experience of being human is not perfect when the capacity for motivated and targeted action (for example, to strive toward the money heap) is missing.

Ksenia, who liked to tell humorous stories, seldom chose a topic that dealt with a crisis situation. It was probably for this reason that right after describing the present situation she switched to a reminiscence of the past when she was capable of motivated and targeted action. The event that she chose to describe was the celebration of Good Friday, a holiday of religious importance. As cultural models or schemas acquire a motivating force when they become part of a person's self-conception, Ksenia's reference to celebrations in several similar interview situations when she was free to choose the topic indicates that religious holidays remained part of Ksenia's identity despite of her living in a new cultural context.

Ksenia's narratives of the celebration of various (religious) holidays during her life in Setumaa related her to the world through actions that an active and vigorous person was supposed to perform in the Setu cultural context. The fact that holidays were important to Ksenia during various stages of her life points to the fact that holidays could relate to various cultural schemas used for self-comprehension. In case holidays would have had meaning only as social events, they would not have had a very high potential in acquiring such a central position in the self-conception of Ksenia who resided in a block of flats in Tartu. The position was achieved via religious meaning: in addition to social relations this also included relations with supernatural beings (resp. Christian saints). The role and importance of relations with other people and with supernatural beings depended on the period as well as on the situation in Ksenia's life. On November 4, 2003 my colleague Andreas Kalkun asked Ksenia if she had been to Mõla Church. ${ }^{7}$ Ksenia answered that she 
had visited, once. Ksenia could not, however, answer any further questions about the saint of the church as according to her, she had been to the church as a young girl who was not interested in the 'affairs of God' but the opportunity to meet other young people.

Ksenia therefore admitted that the cultural models that had motivated her depended on the period of her life. Contact with supernatural beings like St. George had emerged in older age as well as during crisis situations during other periods. If Ksenia never told the legend of St. George on her own initiative and its plot did not develop with every following narration (Metsvahi 2003, 2002), then a personal experience narrative concerning Ksenia's recovery thanks to St. George came up at various times during the interviews on Ksenia's initiative and acquired new aspects each time it was narrated. On our fourth visit to Ksenia, for example, we learnt that the story of recovery was preceded by another story: during Ksenia's illness an old man appeared in Ksenia's dreams, advising her to pray to St. George in order to get well (Metsvahi 2003: 1925; Metsvahi 2002: 312). This indicates that an experience of recovery remembered in this manner was of higher importance in Ksenia's present life than her experience of visiting the Mõla Church during her younger days. The visit to the Mõla church would not appear in(to) the conversation on Ksenia's initiative. If Andreas Kalkun had not taken up the topic, Ksenia had probably never told us that she had visited Mõla church.

Via religious connotations of holidays, place and time form a symbiosis of a special kind through the saint to whom the church is dedicated. ${ }^{8}$ During the interviews conducted with her, Ksenia repeatedly referred to the time of an occurrence of an event that was not related to any religious holidays through holidays. In some cases she first mentioned the place where the church dedicated to the saint, on whose feast day the event occurred was located, only then actually mentioning the name of the saint or the holiday. This indicates that information concerning the church and the holiday related to the saint to whom the church is dedicated to were closely connected in Ksenia's mind.

A holiday was a holy event regardless of Ksenia's location. This always applied to holidays of higher importance that were not related to one specific church but were celebrated in all churches in 
Setumaa as well as in Tartu. Easter was certainly one such holiday and therefore Ksenia could use it as part of a self-scheme of her Tartu-period. Through the scheme the holiday is tied with the individual's world and motivates him/her to act in a certain manner. As Ksenia's acting capacity in her current situation was limited to a minimum - apart form the capacity for verbal self-expression she had no acting capacity - 'real action' was replaced by verbal activity of narration. Ksenia did not use narrating in order to attempt to change the world via verbal expression, long for days gone by, or preach to younger people. Ksenia did admit that the times had changed but she did not protest against it. For example, during our seventh conversation (4.11.2003) after finishing a legend that she related to her patron saint Kseniia Blazhennaia, Ksenia uttered the following words: "So the story goes... yes, this is how it was in the older days. But now... now there is no God or Judas [Laughs]." (ERA, MD $110(12)$ ).

Ksenia used her capacity for verbal self-expression first and foremost for making herself useful: for telling folklorists tales and other issues that interest them. By telling these stories (and via small insertions of other matters onto these stories) she realized, albeit without being aware of this, her identity project, relating the ways of self-conception characteristic of traditional society as well as selfreflexivity typical of contemporary society.

Ksenia realized her identity project with a generally positive frame of mind: in places where the past was juxtaposed to the present, she softened the conflict with laugher; in places where she had told about a crisis situation, she continued with a more optimistic topic. As the Easter was approaching, the description of this holiday was something that related Ksenia to the world and defined her identity as a member of the Setu cultural community in a positive manner, without having to resort to negation and juxtaposition.

Translated by Leena Kurvet-Käosaar

\section{Comments}

${ }^{1}$ The Setu are an Orthodox ethnic group in Southeast Estonia, while the rest of Estonia is dominantly Lutheran. 
${ }^{2}$ Anthropologist Vincent Crapanzano has employed an interesting strategy in his fieldwork on Moroccans: "Sometimes I was silent for more than five or even ten minutes. Then my interlocutors, who no doubt found the silence as unbearable as I did (and were without the "research justification" with which I was defended) began to talk. They described in greater detail what had been happening in their personal and family lives when they committed the ritual fault. They had switched registers." (1999: 81). Our conversation did not have pauses of such length.

${ }^{3}$ It is interesting to note, however, that even today, a number of cognitive scientists believe in the possibilities of making progress in investigating human mind with the help of machine analogy. Zenon Pylyshyn claims that "at the most abstract level the class of mechanisms called computers are the only known mechanisms that are sufficiently plastic in their behavior to match the plasticity of human cognition" (1989: 52). It is also noteworthy that every period's metaphors elaborating the processes of thought reflect the lexical resources of the period concerning technical progress. For example, Estonian idiom "mul jooksis mõte kokku" (my thought 'crashed') demonstrates how computer-related metaphors have become part of our everyday language.

${ }^{4}$ Cognitive unconscious is believed to be formed of those theoretical cognitive mechanisms that exceed the neural level and that about the existence of which there is sufficient evidence but which cannot be accessed consciously (Lakoff \& Johnson 2001: 112).

$5 \quad$ One important way cultural schemas like achievement or love or work or marriage become high-level goal-schemas in individuals' goal hierarchies, I want to say, is by supplying us with our understandings of ourselves. (Quinn 1992: 91).

${ }^{6}$ Antonio Damasio, basing his research on patients with brain injuries, has discovered that when deprived of emotions, people are also incapable of acting in rational manner and planning their future. These findings allow to conclude that the systems of our brain responsible for reasoning and decision-making as well as those for emotions and feelings coincide (Damasio 1994).

7 The Church in Mõla (Russian Maly) village, not far from Izborsk, was a well-known site of religious feasts among the Setu. The most important of the holidays was Mõlapäev 'a day of Mõla' that was celebrated on the first Sunday after St. Peter's and St. Paul's Day (July 12). According to the popular legend, a heavy snow fall had struck the area once in July and only thanks to the prayers in Mõla church the snow melted and no crop failure ensued. In all probability Ksenia participated in the celebration of this 
holiday as a young girl. The ordinary parish feast was celebrated in Mõla on June 25 to commemorate the pious monk Onufrii who worked a long time ago in Mõla monastery. (I am indebted to Andreas Kalkun for this detailed comment.)

8 The interrelatedness of place and time is discussed among others by Giddens (1991: 16).

\section{References}

Crapanzano, Vincent 1999. Reflections. Ethos. Journal of the Society for Psychological Anthropology. March 1999. Vol. 27, No. 1, pp. 74-88.

Damasio, Antonio R. 1994. Descartes' Error. Emotions, Reason and the Human Brain. New York: Papermac.

D'Andrade, Roy G. 1984. Cultural meaning systems. Culture Theory. Essays on Mind, Self, and Emotion. R. A. Shweder \& R. A. LeVine (Eds.). Cambridge: Cambridge University Press, pp. 88-119.

D'Andrade, Roy G. 1989. Cultural Cognition. Foundations of Cognitive Science. Michael I. Posner (Ed.). Cambridge: A Braddford Book, The MIT Press, pp. 795-830.

D'Andrade, Roy G. 1992. Schemas and motivation. Human motives and cultural models. R. G. D'Andrade \& C. Strauss (Eds.). Cambridge: Cambridge University Press, pp. 23-44.

Giddens, Anthony 1991. Modernity and self-identity: self and society in the late modern age. Cambridge: Polity Press.

Johnson-Laird, P. N. 1989. Mental Models. Foundations of Cognitive Science. Michael I. Posner (Ed.). Cambridge: A Braddford Book, The MIT Press, pp. 469-499.

Lakoff, George; Johnson, Mark 2001. Philosophy in the Flesh. The Embodied Mind and its Challenge to Western Thought. New York: Basic Books.

Metsvahi, Merili 2002. On the position of the Religious Legend of St. George in the Mental Universe of the Setu Woman Ksenya Müürsepp. Mental Spaces and Ritual Traditions. An International Festschrift to Commemorate the 60th Birthday of Dr. Mihály Hoppál. E. Bartha \& V. Anttonen (Eds.). Debrecen: Dept. of Ethnograpy, University of Debrecen, pp. 307-339.

Metsvahi, Merili 2003. “Ja seal oll’ suur madu...” Püha Jüri legend setu naise Ksenia Müürsepa vaimses universumis. Akadeemia 9, 2003, pp. 1915-1952.

Pylyshyn, Zenon 1989. Computing in Cognitive Science. Foundations of Cognitive Science. Michael I. Posner (Ed.). Cambridge: A Braddford Book, The MIT Press, pp. 49-91. 
Quinn, Naomi \& Holland, Dorothy 1987. Culture and cognition. Cultural models in language and thought. D. Holland \& N. Quinn (Eds.). Cambridge: Cambridge University Press, pp. 3-40.

Quinn, Naomi 1992. The motivational force of self-understanding: evidence from wives' inner conflicts. Human motives and cultural models. R. G. D'Andrade \& C. Strauss (Eds.). Cambridge: Cambridge University Press, pp. 90-126.

Simon, Herbert A. \& Kaplan, Craig A. 1989. Foundations of Cognitive Science. Foundations of Cognitive Science. Michael I. Posner (Ed.). Cambridge: A Braddford Book, The MIT Press, pp. 1-47.

Spiro, Melford E. 1984. Some reflections on cultural determinism and relativism with special reference to emotion and reason. Culture Theory. Essays on Mind, Self, and Emotion. R. A Shweder \& R. LeVine (Eds.). Cambridge: Cambridge University Press, pp. 323-346.

Spiro, Melford E. 1987. Culture and Human Nature. Theoretical Papers of Melford E. Spiro. B. Kilborne \& L. L. Langness (Eds.). Chicago: The University of Chicago Press.

Strauss, Claudia 1992. What makes Tony run? Schemas and motives reconsidered. Human motives and cultural models. R. G. D'Andrade \& C. Strauss (Eds.). Cambridge: Cambridge University Press, pp. 197-224. 